\title{
Associações Religiosas. Natureza Jurídica
}

\author{
Antônio Chaves \\ Diretor da Faculdade de Direito e Catedrático de \\ Direito Civil na Universidade de São Paulo
} cional.

A Igreja Católica tem personalidade jurídica interna-

Resta saber se ela, e as diferentes frações em que se apresenta na ordem interna: dioceses, paróquias, cabidos, confrarias, irmandades, fábricas, ordens monásticas, etc. - serão pessoas jurídicas, e, em caso afirmativo, se de Direito Internacional Público ou de ordem privada.

Sob este aspecto, na verdade, ela não se apresenta em sua unidade, mas fragmenta-se, como decorrência das necessidades de sua atuação.

Registram-se, a propósito, três correntes doutrinárias. Na primeira coloca-se LACERDA DE ALMEIDA, sustentando tratar-se de pessoas de Direito Público.

Reconhecendo, embora, ser geralmente admitida a personalidade jurídica internacional da Igreja, qualifica de singular, em seu aspecto lógico, a doutrina que contesta a sua personalidade civil, isto é, sua capacidade de Direito Privado, negando-lhe no caráter de todo àquilo que admite no tocante a cada de suas partes:

"A personalidade da Igreja como todo, personalidade distinta da de cada uma de suas divisões ou partes, resulta da própria natureza orgânica da Igreja; e assim como o Estado é pessoa jurídica a que se subordinam outras constituídas pelas suas divisões e partes, assim também a Igreja, a qual não se concebe sem a personalidade, que reconhecemos nas coletividades particulares em que se subdivide".

Na segunda posição está CLóvis BEviLÁQUA, quando sustenta que sob esta relação está a Igreja Católica, face ao nosso 
direito "na mesma situação em que outra qualquer seita, cujos crentes se reúnam em corporações ou instituam fundações".

Afastado o Direito Internacional Privado que aqui nada tem que ver, o Direito Internacional Público é a expressão jurídica da organização nacional como entidade política.

Estruturando-se, politicamente, o Estado é soberano. Todas as entidades, que vivem dentro da esfera de sua organização, devem ser-lhe, necessariamente, subordinadas, ao menos sob certas relações, pois é inadmissível, perante a lógica e perante os fatos, que dentro do Estado exista uma associação que tenha poder jurídico igual ou superior a ele. Se a Igreja não pode ser subordinada ao Estado, é porque não vive dentro dele, sendo mais extensa e substancialmente diversa, se não está submetida ao Direito Constitucional do Estado não é possível considerá-la pessoa jurídica de direito interno.

O que dizia da Igreja católica, em geral, devia, por identidade de razão, ou por via de conseqüência, dizer-se das suas divisões locais, dioceses e paróquias, que serão pessoas de Direito Público eclesiástico, mas, em frente do Direito secular, somente poderiam aparecer como associações de caráter privado, se se organizarem segundo os preceitos de Direito Civil.

Não sendo uma pessoa de Direito Público interno, mas sendo-o do externo, não se lhe podia recusar o exercício de direitos civis. Mas, por outro lado, também não podia negar ao Estado soberano a prerrogativa de regular o seu direito interno, segundo os conselhos da prudência, provendo à sua paz e conservação.

"Por isso, podendo determinar o modo pelo qual as pessoas jurídicas externas exercem direitos privados no país, e as pessoas jurídicas internas se organizam, o Estado vê na Igreja Católica, externamente, uma vasta unidade dirigida pela Santa Sé, e, internamente, uma variedade de corporações e fundações colocadas no plano das outras corporações e fundações, que o Direito Privado reconhece e protege."

Para uma terceira corrente, intermediária, o assunto, só encontrará solução definitiva em texto expresso que precisa resolver a dúvida para evitar maiores inconvenientes, admitindo que a personalidade jurídica destas entidades advém do Direito Canônico.

Foi o ponto de vista que acabou prevalecendo no julgamento da apelação cível n. 10.848, em amplo e erudito debate travado no Tribunal de Justiça do Distrito Federal. 
Lembrou o Des. Homero Pinho, em acórdão da Quinta Câmara Civil, publicado no Diário da Justiça da União de 18.03.1952, que, o Estado não cria a âssociação religiosa como pessoa de direito privado, o Código reconhece-a. "Regula-lhe a personalidade, mas não a capacidade, eis que esta é regida pela lei nacional da pessoa que no caso é o Código Canônico."

Demonstra com SARZANA, Manuale di Diritto Constituzionale della Chiesa Cattolica Apostolica Romana, n. 241, que a subordinação de tais associações à autoridade eclesiástica lhes é inata, tem caráter institucional, o que vale dizer que independente de convenção expressa dos fiéis no respectivo compromisso, são criadas e controladas pela competente autoridade eclesiástica.

E o que se denomina "ereção canônica" que para LACERDA DE ALMEIDA, pág. 148, nota 5, consiste "na aprovação dos estatutos ou compromissos das mesmas pelo Ordinário e autorização para exercerem os atos de devoção em tal ou tal igreja, altar ou capela, Concílio Tridentino seção: 22 de Ref. 8 ".

Carvalho Mourão reconhece, no caso, "no direito canônico" o valor de norma geral obrigatória, não o caráter de lei, mas o de estatuto das associações e das fundações. A norma do direito canônico, depois da separação da Igreja e do Estado, perdeu o caráter de norma legal, mas tem o de norma estatutária; por conseguinte, ao regular a capacidade dos administradores, dos associados, entre si e com terceiros, nas associações religiosas ou fundações, não podemos deixar de aplicar como norma estatutária o direito canônico. Do contrário, essas associações ficariam num estado caótico e anárquico (sem norma legal). Assim como os Estatutos, votados pelos acionistas, constituem norma obrigatória, naquilo em que não forem contrários à lei, em se tratando de sociedades (associações em geral) é o direito canônico estatuto das associações e das fundações religiosas, no silêncio, ou na falta do Estatuto ou compromisso" (voto no acôrdão 26.08.1940, in Rev. Forense, volume 6, pág. 354, Direito, volume 6, pág. 264).

DUARTE DE AZEvedo, Controvérsias Jurídicas, assinala ser destituído de procedência pretender, a pretexto da separação da Igreja do Estado, que as dioceses, a Mitra, os cabidos, os conventos, as Irmandades e mais pessoas jurídicas eclesiásticas passaram a se subordinar apenas às leis civis, relegando as da Igreja que as constituíram e as regularam.

"A separação da Igreja exautorou-a de seu caráter oficial perante o Estado. Extinto o regime 
de aliança, os institutos eclesiásticos de públicos se tornaram particulares, mas as pessoas jurídicas na Igreja nada perderam de sua constituição e personalidade."

É bem mais importante do que poderia parecer à primeira vista a distinção estabelecida.

Nunca poderiam supor os que traçaram os limites entre a Igreja e o Estado - aditou o des. FrANCISCo PEREIRA DE BulHões CARVAlHo, - "que as corporações religiosas, subtraídas à fiscalização do Estado, por motivo de respeito à disciplina interna da Igreja, fossem recusar-se à disciplina da Igreja, sob o fundamento de terem uma autonomia que, jamais em qualquer tempo da história, lhes havia sido reconhecida. ."

Devia tremer a mão do juiz que mandar entregar ao arbítrio de meia dúzia de administradores, sem fiscalização nem do Estado nem da Igreja, um grande patrimônio amealhado com o correr de anos e de séculos para fins religiosos ou de beneficência.

Devia tremer ainda mais ao proclamar o caráter leigo de associações com a finalidade declarada nos seus Estatutos de promover o serviço e culto da religião católica.

"Será grande a responsabilidade daquele que considerar as confrarias e irmandades católicas meras sociedades civis, permitindo assim que a qualquer tempo, na forma do art. 21 n. 1 do Código Civil, possam ser dissolvidas pela simples vontade da maioria dos seus sócios eventuais, e, na forma do art. 22 do mesmo código, possa seu patrimônio, que, pelo destino que lhe era traçado, tomou o caráter perpétuo e inviolável de verdadeira Fundação, ser partilhado entre os sócios, num verdaderio atentado ao interesse social."

A única solução razoável, em matéria de associação religiosa, é uma concordata com o Vaticano, preconizada sob invocação do precedente do governo italiano, que dividiu as confrarias em duas categorias, conforme tenham ou não o escopo exclusivo ou predominante do culto.

"No caso afirmativo, tais confrarias permaneceram expressamente na dependência da autoridade eclesiástica em quanto diga respeito ao seu funcionamento e administração (Concordata, art. 29, letra 
"c", na conformidade dos cânones 688 e 725 apud SchiapPoLI, in Nuovo Digesto Italiano, volume III, Confraternite, pág. 817).

Quanto às confrarias que, embora de culto, tenham como escopo exclusivo ou predominante o de beneficência, ficaram equiparadas às instituições públicas de beneficência e submetidas à tutela e inspeção do poder civil, intervindo o Ordinário somente em matéria religiosa (CAvigioli, Derecho Canonico, 1, pág. 569).”

Não há, na verdade, outra saída para o embaraço senão uma concordata, pois, a rigor, só poderiam ser consideradas como entidades de direito privado as sociedades religiosas que como tais fossem reconhecidas pelo direito positivo, que, num círculo vicioso, não pode reconhecê-las sob a invocação de sua laicidade.

Encontramo-nos em posição bem semelhante à que ocorria na Itália há meio século, antes da Concordata que se tornou executória com a Lei n. 810, de 27.05.1929. A rigor, deixando a evidência, deveríamos admitir como pessoas jurídicas de fato, e, pois, inexistentes aos olhos da lei, grande número de ordens, congregações e outras entidades religiosas.

Somente por meio de um diploma legal dessa natureza será possível rever a legislação brasileira e a própria legislação canônica, traçando diretrizes a serem observadas por ambas as partes, indicando-se as personalidades jurídicas que vão ser objeto de expresso reconhecimento.

Enquanto semelhante concordata não for alcançada, melhor definindo as posições recíprocas, há que reconhecer que entre os dois sistemas vigorantes de relações entre confissões e o Estado: separatista em sentido próprio, submissão das confissões ao direito das associações privadas, ou privilegiado em favor de uma ou mais religiões, o Brasil, como os Estados Unidos da América do Norte, optou pelo primeiro, que permite às confissões e associações religiosas viverem livremente.

Se entendem, porém, inserir-se "no ordenamento estatal (por exemplo obter o reconhecimento da personalidade jurídica)" - acentua PIETRo Gismondi, L'Autonomia delle Confessioni Acattoliche, in "Raccolta di Scritti in Onore di ARTURo CARlo Jemolo", vol. I, Diritto Canonico, Diritto Ecclesiastico, tomo II, Milão, Giuffrè, 1963, págs. 633-662, — devem sub- 
meter-se às normas de direito comum e apresentar-se como corporações nas formas típicas" elaboradas pelo ordenamento estatal, em virtude do qual não se concebe o reconhecimento das confissões e das suas entidades pela livre regulamentação dos seus estatutos:

Lembra que a contraposição entre confissões e associações com finalidade religiosa, consiste em que as primeiras apresentam caráter institucional em virtude da existência de uma comunidade permanentemente ligada pelo vínculo da fé eomụm, e, além disso, uma organização, uma verdadeira e própria normação, foi acolhida em acórdão de 1958 da Corte constitucional italiana, que ressaltou dela se desatarem:

“todas as conseqüências, entre liberdade de exercício dos cultos acatólicos coma pura manifestação de fé religiosa e a organização das várias confissões nas suas relações com o Estado".

Encarece que as confissões religiosas diferentes da cató,lica dã̃o origem a organizações extremamente diversificadas entre si, que existe desconformidade entre comunhões sociais com finalidade religiosa surtas com ordenamentos próprios específicos originariamente não conexos com as estatais, e os agrupamentos de fato, sem qualquer organização mesmo elementar, fazendo ver que a adesão a uma doutrina religiosa é diferente da manifestação de vontade que intervém na conștituição ou na adesão a ưma determinada associação.

"Além disso é evidente que os ordenamentos das confissões não são derivados e são portanto estranhos ao ordenamento estatal, por estarem constituídos e desenvolvidos fora dele, mas são abrigados a colocar-se em relação com o próprio ordenamento estatal, consentindo reciprocamente que algumas matérias sejam reguladas pela normação do outro ordenamento."

Invoca o pensamento de JEMoLo: reconhecer os direitos de liberdade religiosa significa garantir aos sectários de todas as confissões o uso dos necessários meios instrumentais, aî encontrando confirmação indireta da tese que se o Estado quer garantir integralmente a liberdade natural da pessoa não pode não reconhecer relevo jurídico também às comunidades, nas quais se desenvolve e se integra à personalidade do indivíduo, com os interesses correspondentes. 
Acentua que a orientação corresponde à aspiração substancial do homem moderno de combater a solidão, à qual estaria fatalmente destinado, tendo BETTI, acentuado que "quanto mais sentida é a solidariedade entre os sócios, tanto mais acentuadas tornam-se as exigências da sociedade também na regulamentação da autonomia privada".

Com relação aos demais cultos religiosos, alguns, pela relevância que assumem, têm reconhecidas as entidades respectivas por diplomas legais.

Assim o Decreto italiano n. 1.731, de 30.10.1930, deu ordenamento especial às Comunidades israelitas, entidades jurídicas que provêm à satisfação das necessidades religiosas, na conformidade das leis e tradições hebraicas.

Cuidam do exercício do culto, da instrução e da educação religiosa, promovem a cultura, e administram instituições assistenciais e beneficentes.

\section{Associações religiosas em espécie}

Existe grande número e grande variedade delas, nem sempre sendo possível estabelecer limites precisos entre as sociedades religiosas e as civis.

Procuremos sistematizar a matéria, acompanhando principalmente LACERDA DE ALMEIDA, no estudo a que procedeu, sob o título de Pessoas Jurídicas, em seus tópicos essenciais.

As Dioceses. A Igreja em sua universalidade constitui pessoa jurídica; devem formar outras tantas pessoas as suas subdivisões, dotadas de regime e vida próprios, como as dioceses sob a autoridade dos bispos e as paróquias sob o governo dos párocos. Sob o aspecto da independência do regime, embora subordinada, como outras sociedades igualmente autônomas a uma sociedade mais elevada e vasta, a personalidade da diocese não oferece dúvida.

A polêmica só se agita no tocante à propriedade, administração e disposição dos bens.

No Direito Eclesiástico Protestante a questão não tem dificuldade: os bens eclesiásticos pertencem à comunhão dos fiéis; sua administração pode variar conforme o sistema para isso adotado, a personalidade jurídica resulta da própria existência do patrimônio pertencente à Igreja coletivamente tomada.

Perante a doutrina católica, porém, é controverso a quem pertencem os bens eclesiásticos, e que caráter têm, visto que 
a propriedade dos mesmos dissemina-se em fundações e instituições pias, algumas a cargo dos bispos, mas nem por isso confundindo-se com o patrimônio da mitra ou da própria Igreja diocesana.

Isso não impedia ser verdade a existência da Diocese como pessoa jurídica.

“Em primeiro lugar porque para sê-lo não é necessário a qualidade de proprietária dos bens que estejam sob sua administração bastando-lhe o exercício dos direitos que lhe competem sobre tais bens, principalmente o de excluir a outrem v.g., o Estado ou qualquer outra corporação do gozo e posse de tais bens, e é o que basta, nas relações da Diocese com as outras corporações e com o Estado.

Em segundo lugar porque não é necessário também a existência de um patrimônio in actu para que seja reconhecida a existência e capacidade de uma corporação ou de um ente jurídico de existência ideal, bastando a possibilidade de adquirir esse patrimônio; e ninguém dirá que uma doação ou legado feito à Diocese caducará por falta de capacidade jurídica da legatária.

Em terceiro lugar, finalmente, porque os cânones atribuindo aos bispos todo o poder sob a Igreja à sua direção confiada, dão-lhes direitos sobre os bens compreendidos na Diocese, direitos que se não poderiam compreender nem praticar se a cada uma das instituições fosse livre reger e administrar como entendessem o respectivo patrimônio e constituíssem, nesse caráter, entidades não subordinadas ao Bispo, mas inteiramente isentas da sua inspeção e governo."

Da Diocese, representada pelo Bispo como chefe da respectiva Igreja - a qual é corporação —, distingue-se a mitra, por ser um patrimônio destinado a manter a entidade Bispo como pessoa indeterminada que ocupar a qualquer tempo a sede episcopal e fundação. Aquela, como ser individual, perece; esta goza de uma espécie de imortalidade legal, na frase de BLACKSTONE, constituindo o que os juristas ingleses denominam sole corporation ou corporação de um só, série das pessoas singulares que ocupam sucessivamente certa dignidade ou cargo. E porque essa série é indefinida e a sucessão perpétua, surgiu 
a necessidade de estabelecer patrimônio destinado a mantê-la no decurso dos tempos - daí sua natureza de fundação.

As Paróquias. "À medida que foram aumentando e complicando as atribuições dos bispos, crescendo a população e dilatando-se os limites das dioceses, entraram os bispos a nomear presbíteros que os auxiliassem na administração dos sacramentos e outros misteres da cura de almas em certos pontos da diocese, vindo com o andar dos tempos a tornar-se estáveis e perpétuas tais delegações.

Com o caráter de perpetuidade e inamovibilidade atribuído aos párocos nasceu a fixação e estabilidade dessa circunscrição eclesiástica denominada - paróquia - a qual, não raras vezes tem sido tomada pela lei civil para termo de divisão aplicável a vários fins de ordem meramente civil.

É pois, como o município, uma divisão antiqüíssima, com interesses próprios, distintos dos interesses da diocese, de que faz parte, com sua Igreja, com seu chefe e representante, e pois tem direito a personalidade jurídica, e em tal caráter lha reconhecem os autores e o confirma a jurisprudência dos nossos tribunais. Assim, praticado um ato da autoridade civil que diga respeito à paróquia, tem o pároco competência para tomar parte nele ou reclamar contra ele, defendendo e sustentando os direitos de sua igreja."

Os cabidos. Como conselheiros natos do bispo, os cônegos formam o senado dele, assim como os cardeais o do Papa, e do mesmo modo que estes ajudam e servem ao Papa no governo da Igreja Universal, aqueles prestam os mesmos ofícios aos bispos no regime das respectivas dioceses.

"Em corporação separada do bispo, constituem o capítulo ou cabido, o qual tem incontestavelmente personalidade jurídica, pois distingue-se dos seus membros, tendo como têm honras e jurisdição que não tem nenhum dos cônegos tomados separadamente, e que desenvolve principalmente em sé vaga."

Nota-se-lhe, além disto, o caráter de perpetuidade e renovação ou duração indeterminada pela substituição dos respectivos membros; tem direitos e interesses como corporação, bens patrimoniais, síndico ou procurador, e selo para expedir os atos capitulares, o que tudo implica a personalidade que lhe compete. $\mathrm{O}$ cabido, pois, tem representação jurídica ativa e passiva tanto pelo patrimônio que administra, como por qualquer outro direito que lhe compita. 
Cabido ou capítulo tem sentido amplo: significa a corporação de clérigos instituída em certa Igreja para prover ao serviço do culto, e assim diz-se o capítulo da Ordem Beneditina quando incorporada a Ordem para deliberar. No sentido restrito toma-se pelo capítulo dos cônegos da Catedral.

Confrarias ou irmandades. Define-as LACERDA DE ALMEIDA como associações de leigos sob a autoridade e inspeção dos bispos destinadas à manutenção do culto e ao exercício de atos de piedade.

Vocábuilo derivado do francês, confrérie, as irmandades podem tèr várias finalidades: meramente religiosas, auxílios espirituais aos próprios componentes ou obras de piedade ou de caridade, e tomam várias denominações: Confraria do Santíssimo Sacramento, das Almas, da Misericórdia, do Espírito Santo, etc.

As pessoas que as compõem, embora crentes na mesma fé, não estão sujeitas a votos religiosos ou de obediência, anota DE PLÁcido E Silva, acrescentando:

"Embora associações de caráter espiritual e religioso, subordinadas às autoridades religiosas, a fim de que adquiram personalidade jurídica, precisam atender às prescrições legais prestando, assim, obediência às leis e autoridades civis.

Em relação à sua organização interna administrativa, as confrarias, quando eretas canonicamente encontram-se subordinadas à autoridade eclesiástica.

Deste modo, fundados nos compromissos ou regulamentos das irmandades ou confrarias, os atos episcopais são rigorosamente válidos para intervir nas administrações delas no sentido de levá-las ao cumprimento de seus objetivos ou de lhes normalizar qualquer controvérsia ali verificada.

Somente quando se trata de matéria de ordem temporal, sujeita às regras do direito civil, deve intervir a autoridade leiga, desde que, em tais casos, não se trate de assuntos pertinentes à sua administração interna, sujeita à jurisdição eclesiástica".

\footnotetext{
"São de ordinário eretas em uma igreja ou capela" - volve LACERDA DE ALMEIDA — "e têm a seu cargo uma devoção, às vezes uma ou mais instituições de caridade. Desta última espécie são as Misericórdias, que têm a seu cargo hospitais, cemitérios e asilos; são de ordinário entre nós a pessoa jurídica encarregada de funções pias.

Distinguem-se das devoções em que estas são meras congregações de fato sem compromisso ou
} 
estatutos, que são a base de toda a associação organizada, entretanto as devoçōes podem usar opa como irmandades...

Com o advento da República e proclamação dos princípios de liberdade religiosa assegurados pela Constituição, cessou por completo, a ingerência do poder civil na administração das irmandades e a fiscalização a que sob diversos pretextos viviam sujeitas...

Se a jurisprudência tem negado aos bispos a faculdade de tomar contas às irmandades da administração de seu patrimônio, também não a tem outorgado aos juízes seculares como dantes, nem pode, por outro lado, desconhecer o direito de suprema inspeção que sobre tais corporaçōes e, conseguintemente, sobre ao destino e aplicação do respectivo patrimônio deve exercer a autoridade eclesiástica".

Fábrica. Para De Plácido e Silva, no sentido que lhe dá o direito canônico tomado o vocábulo na acepção de índole, estrutura ou composição de alguma coisa, significa a expressão não somente o conjunto de bens e de rendas paroquiais destinados à manutenção do culto e da própria conservação da Igreja, como o conselho ou a irmandade, a que está afeta a administração de tais bens e rendas, sob inspeção das autoridades eclesiásticas.

"Correspondendo ao patrimônio paroquial e ao poder administrativo temporal, que o rege, cujos membros se dizem fabriqueiros ou fabricanos, é a fábrica paroquial uma pessoa jurídica de direito privado, embora subordinada aos poderes eclesiásticos, a que cabe a sua direção e fiscalização.

Diz-se simplesmente temporal, em oposição a espiritual, porque atende simplesmente aos negócios temporais (profanos ou econômicos e financeiros) da Igreja, podendo ser constituído simplesmente por leigos, enquanto o poder espiritual somente é representado pelos párocos ou pelos clérigos.

As fábricas paroquiais regem-se segundo as regras do Direito Canônico, estando diretamente subordinadas às autoridades eclesiásticas, mesmo quando constituídas por leigos, componentes das irmandades, congregações ou confrarias.

Quando os bens são instituídos por uma pessoa, com a cláusula de inalienabilidade e sob cota certa e determinada, para mantença de um culto, eles se dizem propriamente capela.

"Pessoa jurídica de Direito Canônico; consiste nos bens ou rendimentos destinados à conservação e reparação de uma igreja, de ordinário paroquial ou catedral, bem como às despesas 
do culto", classifica-a LACERDA DE ALMEIDA, como universalidade de bens administrados entre as fundações, pois nada mais é que um patrimônio destinado àqueles fins.

\footnotetext{
"Mas como as necessidades econômicas da Igreja consistem precisamente ná conservação e reparação do edifício, altares, móveis, alfaias e guisamento, e mais despesas com a manutenção do culto; a fábrica representa a Igreja sob a relação patrimonial; é o fisco de cada igreja, como o fisco é a personificação patrimonial do Estado e de suas divisões políticas ou administrativas".
}

Ordens monásticas. Em nenhumas outras corporações é mais visível - diz o mesmo tratadista - a nota de unidade na multiplicidade, de inteira fusão e absorção da vida individual na vida coletiva, do que na organização das ordens monásticas.

Os três votos - comuns a todas as regras - de pobreza, obediência e castidade, o estão indicando. 0 voto de pobreza implica inteira renúncia à propriedade individual em benefício da comunhão: pouco importa que a ordem seja rica ou mendicante, o religioso é sempre pobre.

$\mathrm{O}$ advento da República, proclamando a liberdade de consciência e de associação, não melhorou a princípio a situação em que se achavam as comunidades religiosas, até que a Constituição de 24-02-1891, garantindo a todas as confissões religiosas o direito de adquirir bens, aboliu implicitamente o regime de mão-morta.

Quanto à administração dos cemitérios, foi retirado da Constituição de 1967, e não incluído na de 1969, o preceito constante do art. 141, § 10 da de 1946, atribuindo-lhes caráter secular e determinando sua administração pela autoridade municipal, permitindo a todas as confissões religiosas praticar neles os seus ritos e autorizando as associações religiosas a, na forma da lei, manter cemitérios particulares.

A inovação é de importância fundamental, uma vez que autoriza a interpretação de que é livre a organização de sociedades para fins de exploração de cemitérios.

Permanecerá, no entanto, como é lógico, a distinção entre os cemitérios públicos e os particulares. 